\title{
Adapting the NADI ${ }^{T M}$ Concept to Heavy Duty Engines
}

\author{
T. Colliou' ${ }^{1}$ R. Tilagone ${ }^{1}$ and B. Martin ${ }^{1}$ \\ 1 IFP-Lyon, BP 3, 69390 Vernaison - France \\ e-mail: thierry.colliou@ifp.fr - richard.tilagone@ifp.fr - brigitte.martin@ifp.fr
}

Résumé - Adaptation du concept NADI ${ }^{\mathrm{TM}}$ aux moteurs de poids lourd — Le moteur diesel est particulièrement bien adapté aux motorisations de véhicules poids lourds mais doit encore être amélioré. Le compromis sur les émissions NOx/particules doit encore être amélioré tout en maintenant un rendement élevé malgré l'augmentation des puissances spécifiques. Si la technologie de post traitement SCR est prête pour atteindre les objectifs fixés par les normes Euro $\mathrm{V}$ et les suivantes, les combustions de type HCCI (Homogeneous Charge Compression Ignition) ou HPC (Highly Premixed Combustion) offrent également un fort potentiel pour atteindre les futurs niveaux d'émission de NOx et de particules.

En réponse à ces nouveaux challenges, l'IFP a développé un système de combustion capable d'atteindre de très bas niveaux de particules et de NOx tout en maintenant un niveau de performance comparable à un moteur diesel traditionnel en combustion standard. Ce moteur bi mode appelé NADI ${ }^{\mathrm{TM}}$ (pour Narrow Angle Direct Injection) autorise des combustions HCCI à charge partielle et commute sur des combustions conventionnelles pour atteindre les exigences des fortes charges.

Ce papier présente les derniers développements de ce concept sur moteur monocylindre et les améliorations obtenues en terme de plage d'utilisation des combustions HPC, d'émissions de CO et de $\mathrm{HC}$, de consommation de carburant et du bruit de combustion. À pleine charge, la chambre de combustion $\mathrm{NADI}^{\mathrm{TM}}$ est comparable aux chambres actuelles avec cependant une légère augmentation de la consommation et des émissions de fumée.

En combustion HPC une PME de 13 bar a été atteinte à mi-régime du cycle ESC avec un niveau de NOx inférieur à $0,3 \mathrm{~g} / \mathrm{kWh}$ ce qui est environ 25 fois plus faible qu'un diesel classique. Les émissions de particules sont comparables avec le niveau du moteur standard. Les émissions de $\mathrm{CO}$ et de HC sont sensiblement supérieures mais restent compatibles avec les performances des catalyseurs d'oxydation actuels.

La pénalité interne de consommation due aux débits d'admission et aux taux d'EGR supérieurs nécessaires pour le contrôle des combustions HPC peut être estimée par un code 0D de la boucle de suralimentation. La puissance de refroidissement de l'air et de l'EGR est également calculée et montre une augmentation importante par rapport au moteur de série pour maintenir la température admission à un niveau acceptable.

La voie de la réduction du rapport volumétrique a également été explorée et permet d'augmenter significativement la plage de fonctionnement HCCI. Les principaux inconvénients proviennent de la difficulté de démarrage à froid et de la chute du rendement de thermodynamique.

Le challenge est maintenant de définir des stratégies d'injection multiple permettant d'étendre la plage HCCI vers les fortes charges et de rendre les conditions de fonctionnement pleinement 
compatibles avec les performances de la boucle de suralimentation et de la puissance des échangeurs à mettre en œuvre.

\begin{abstract}
Adapting the NADI TM Concept to Heavy Duty Engines - Diesel combustion is well adapted for heavy duty engines but the challenge is twofold. On the one hand, the trade off between NOx and particulate emissions has to be improved. On the other hand, efficiency needs to be maintained and the trend is to increase specific power and torque output. If SCR technology is ready to meet Euro IV and beyond, homogeneous charge compression ignition (HCCI) or highly premixed combustion $(H P C)$ are new technologies that also offer great potential for meeting future NOx and particulate emissions regulation targets.

In response to the challenges that the Diesel engine faces, IFP has developed a combustion system which is able to achieve near zero particulates and NOx emissions while maintaining the performance standards of the D.I Diesel engine. This "dual mode" engine application called NADITM (Narrow Angle Direct Injection) applies Homogeneous Charge Compression Ignition at part load and switches to conventional Diesel combustion to reach high and full load requirements.

Thanks to the financial support from European Commission, the "Hy-SPACE" project leaded by IFP, was launched in partnership with Daimler Chrysler, Iveco, Delphi, Volvo, Chalmers University (Contract G3RD-CT-2002-00 787) with the aim to adapt the NADI ${ }^{T M}$ concept to heavy duty engines.

This paper presents the latest developments of the NADI ${ }^{T M}$ concept on a single cylinder heavy duty engine, and the associated improvements regarding HPC (Highly Premixed Combustion) operating range, $\mathrm{CO}$ and $\mathrm{HC}$ emissions, fuel consumption and combustion noise. At full load, the NADI ${ }^{T M}$ system is consistent with present Diesel performances with a slight increase in fuel consumption and smoke level.

In HPC combustion mode, above mid speed of the ESC cycle, a BMEP of 13 bar was achieved with NOx emissions below $0.3 \mathrm{~g} / \mathrm{kWh}$ which is 25 times lower than a conventional Diesel engine. The particulate emissions are comparable to the standard engine level. $\mathrm{CO}$ and $\mathrm{HC}$ emissions were limited and compatible with an oxidation after-treatment catalyst performance.

The penalty resulting from the higher intake flow and EGR rate needed to control the HPC combustion can be predicted by air-loop OD calculations. The cooling power for air and EGR is also important to maintain acceptable intake temperature.

The way to reduce compression ratio was explored and led to a significantly increase in HCCI range. The mains drawbacks are the cold starting conditions and the increase in fuel consumption.

The challenge is now to find appropriate multiple staged injection strategies to extend the HCCI range up to higher load and to be fully compatible with the turbocharger performances and cooler efficiencies.
\end{abstract}

\section{INTRODUCTION}

For many reasons, Diesel combustion is a suitable approach for heavy duty engines but still faces two main drawbacks. On the one hand, the trade-off between NOx and particulate emissions has to be improved to meet the most stringent regulations. On the other hand, specific power and torque must be increased without any loss of thermal efficiency. Selective Catalytic Reduction technology is ready to cope with Euro IV regulations and the following ones, but Homogeneous Charge Compression Ignition (HCCI) or highly premixed combustion (HPC) offer great potential for meeting future NOx and particulate emissions regulation target [1 to 20].

As shown in Figure 1, HCCI or HPC, which concern more or less bulk homogeneous mixture, are located in the area far from thermal NOx and soot formation areas identifying for conventional Diesel combustion with premixed and diffusion flame.

The principle of HCCI combustion consists of:

- preparing a highly diluted air/fuel mixture by burned gases recirculation;

- promoting simultaneous ignition in the whole space of the combustion chamber;

- controlling precisely the combustion heat release to achieve best the compromise in terms of efficiency and pollutant emissions.

The main difficulties are linked to the ability to control combustion speed, to lower pollutant emissions and to avoid oil dilution. One additional aspect is the reduced HCCI range leading to a "dual mode" approach, using the HCCI or HPC 


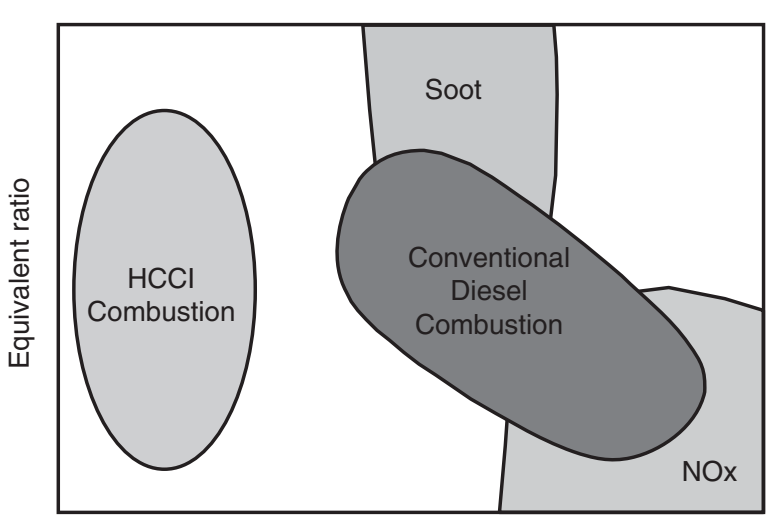

Temperature

Figure 1

Area of HPC/HCCI combustion in an equivalent fuel/air ratio and combustion temperature map.

combustion at low and medium loads and conventional combustion at high load.

IFP has developed a combustion chamber which is called $\mathrm{NADI}^{\mathrm{TM}}$ (Narrow Angle Direct Injection), allowing for good performances with the two combustion modes [1], [6-9].

The general architecture of the engine is very close to a traditionnal diesel engine with some differences listed below:

- narrow spray cone angle to limit fuel liner impingement;

- adapted specific bowl design for fuel wall guiding effect;

- reduced geometric compression ratio;

- multiple stage injection (Common rail fuel injection system).

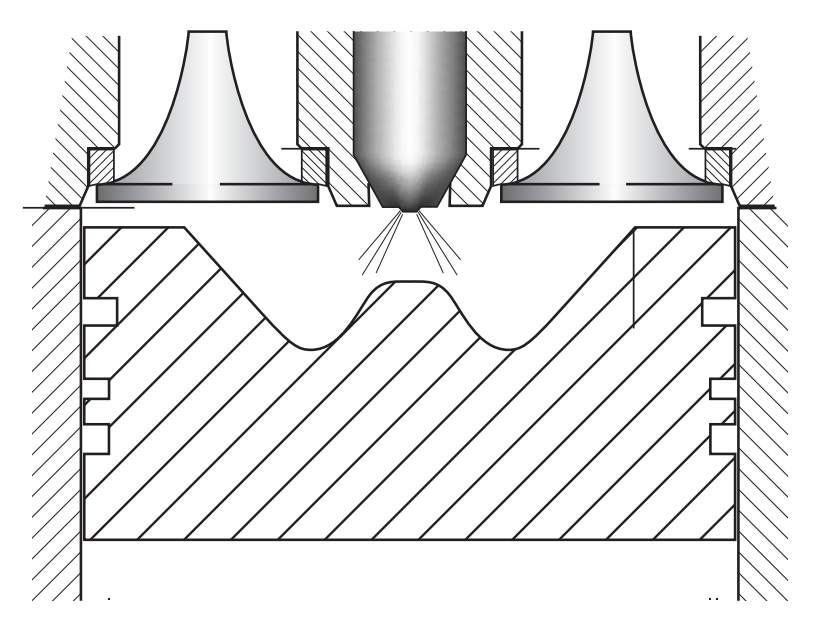

Figure 2

Overview of the NADI ${ }^{\mathrm{TM}}$ combustion system concept.

This paper summarises the results obtained with this concept on a heavy duty application and presents the development of this concept on a single cylinder engine regarding $\mathrm{HCCI}$ or $\mathrm{HPC}$ operating range, $\mathrm{CO}$ and $\mathrm{HC}$ emissions and combustion noise while maintaining very low NOx and particulate emissions.

\section{EXPERIMENTAL SET-UP}

The engine is a single cylinder IVECO Cursor 8 engine with specifications given in Table 1.

No oxidation catalyst was used, so the $\mathrm{HC}$ and $\mathrm{CO}$ emissions reported in this paper are engine out values.

A cylinder pressure transducer was fitted into the cylinder head to record high-speed data at 0.1 crank angle resolution.

TABLE 1

IVECO C8 single cylinder engine specifications

\begin{tabular}{l|l} 
Displacement & 1.31 \\
Bore & $115 \mathrm{~mm}$ \\
Stroke & $125 \mathrm{~mm}$ \\
Connecting Rod Length & $200 \mathrm{~mm}$ \\
Valves per cylinder & 4 \\
Injection system & DELPHI common-rail \\
Compression ratio & Adjustable from 8 to 20 \\
Max. in cyl peak pressure & 220 bar \\
Injection & Up to 8 per cycle \\
Max. BMEP & 20 bar \\
ESC speeds & 1300,1580 and $1870 \mathrm{rpm}$ \\
\hline
\end{tabular}

Heat release analysis was done using a standard OD inhouse code. Exhaust gas emissions of $\mathrm{CO}, \mathrm{HC}, \mathrm{NOx}, \mathrm{O}_{2}$ and $\mathrm{CO}_{2}$ were recorded by Pierburg analysers. An AVL415S smoke meter was used for soot measurement.

\section{Adaptation of the NADI ${ }^{\mathrm{TM}}$ Concept to Heavy Duty Engines}

Developed for passenger car applications, the NADI ${ }^{\mathrm{TM}}$ concept was conceived as a universal concept applicable to any Diesel engine. Its potential is so appealing that the HySPACE project intended at developing clean heavy duty engines decided to try it out.

The dimensions of the heavy duty engines (bore) are well in accordance with narrow cone angle approach expectation in terms of wall wetting.

CFD was used in order to accelerate the adaptation of passenger car know-how to heavy-duty engines. Such an adaptation was carried out by a widening of piston bowl and injector spray cone angle. Several bowls and corresponding injection systems were tested.

At full load, configuration selection was based on power requirements, the NADI ${ }^{\mathrm{TM}}$ chamber with a compression ratio of 14:1 having to provide as much power as the original chamber (compression ratio of 17:1) without any fuel consumption loss and with a peak pressure limit of 220 bar. 
After a few CFD iterations, a bowl design was selected leading to the best compromise between power performances and HPC running. The injector characteristics were also adapted to the new combustion chamber geometry: cone angle, flow, number of holes, as illustrated in Figure 3. The next selection criterion was emissions levels at part load. An operating point was chosen and injection strategies tested on the selected bowls. Results showed that HCCI combustion was favoured by the configuration with the narrowest spray cone angle, indicating that an ideal optimum would need to be found between full load (wider) and part load (narrower) configurations. The narrow configuration was manufactured for test bench investigations.
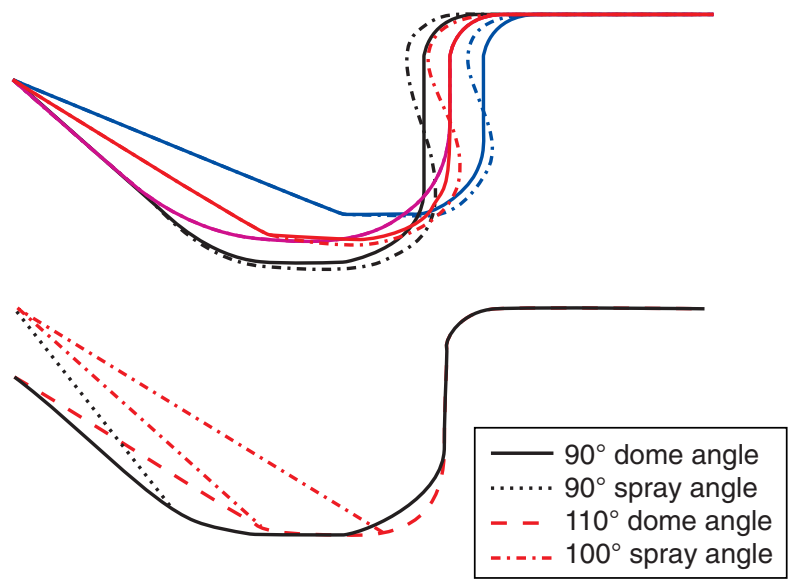

Figure 3

$\mathrm{NADI}^{\mathrm{TM}}$ bowls tested and configurations selected after full load investigations.

All previous HCCI combustion CFD work was performed without any test bench data. Once the selected configuration was manufactured and test bench available a validation of the previous CFD work was performed by computing a test bench HCCI operating point.

Results are illustrated in Figure 4 (in cylinder pressure curve) corresponding to the running condition described in Table 2. The trust put in the CFD tools for piston bowl predesign for part load HCCI operating conditions is confirmed. Two CFD cases are present: one for the theoretical injector static mass flow rate and one with the effective injector static mass flow (that measured on the injector test bed after manufacturing: 1370ml/min@100bar).

TABLE 2

High EGR rate operating conditions for a single cylinder engine

\begin{tabular}{c|c|c|c|c|c}
\hline Rpm & $\begin{array}{c}\text { Air flow } \\
\text { rate }(\mathrm{kg} / \mathrm{h})\end{array}$ & $\begin{array}{c}\mathrm{Q}_{\text {inj }} \\
(\mathrm{mg})\end{array}$ & $\lambda$ & $\begin{array}{c}\text { EGR } \\
\text { rate }\end{array}$ & $\begin{array}{c}\mathrm{P}_{\text {rail }} \\
(\mathrm{MPa})\end{array}$ \\
\hline 1580 & 35.6 & 41.4 & 1.25 & $55.4 \%$ & 140 \\
\hline
\end{tabular}

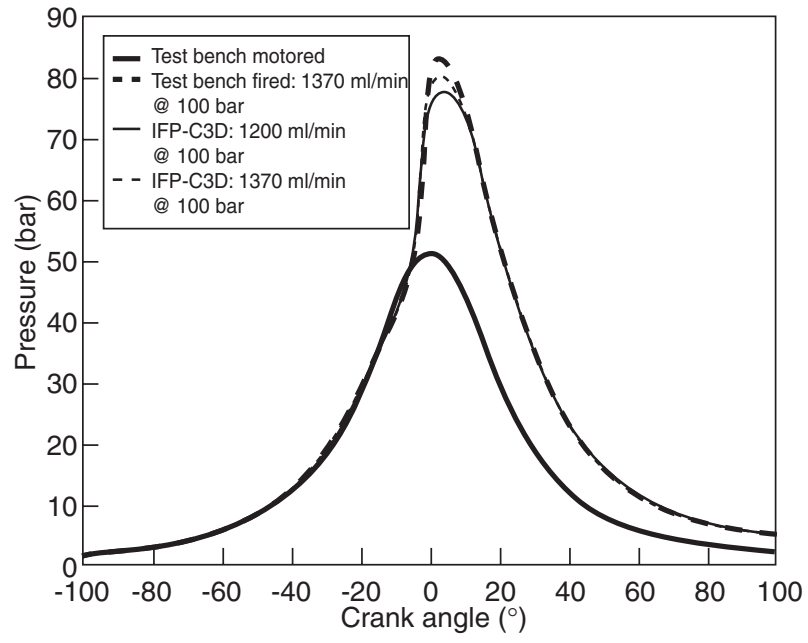

Figure 4

Validation of HCCI investigations.

\section{TEST RESULTS}

\subsection{Conventional Combustion}

As the standard engine is tuned to reach the EURO IV target with SCR and without any particulate filter, the results with the NADI ${ }^{\mathrm{TM}}$ chamber are presented in comparison to the serial chamber with the same NOx emissions level (about $8 \mathrm{~g} / \mathrm{kWh}$ ), Figure 5. If the difference of fuel consumption is limited below $2 \%$, the smoke emissions are slightly increased at B speed (1580 rpm) as presented below.

The higher smoke level obtained at part load condition with the NADI ${ }^{\mathrm{TM}}$ chamber are not detrimental as these points will be run in HCCI combustion, which is characterised by very low smoke level. At higher load, conventional

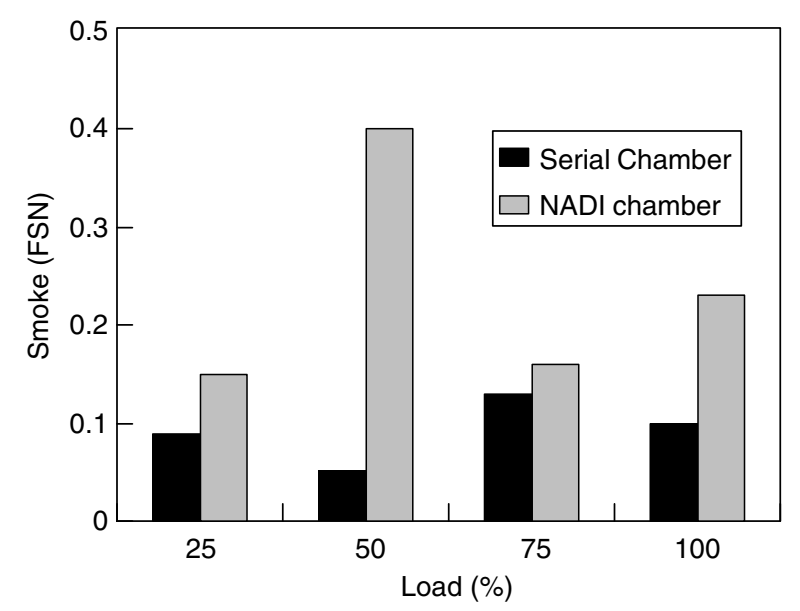

Figure 5

Smoke emissions comparison at B speed (1580 rpm). 
combustion leads to a slight increase of smoke level. In order to reduce the gap in terms of particulate emissions, postinjection is efficient way without any severe damage for fuel consumption. Unburned hydrocarbon and carbon monoxide emissions are slightly higher than the conventional chamber but significantly lower than the Euro V limitation.

\subsection{Homogeneous Combustion}

Several tests in homogeneous combustion were performed on steady-state conditions to improve the performance of the $\mathrm{NADI}^{\mathrm{TM}}$ combustion chamber on the B speed (ESC cycle). Engine parameter settings were optimised looking at EURO V limits without any NOx after-treatment: rail pressure, injection timing, number of injection, EGR ratio, injector mass flow rate and number of hole.

In order to take into account running conditions, limiting factors have been selected:

- Noise: < $95 \mathrm{~dB}$;

- NOx: $<0.3 \mathrm{~g} / \mathrm{kWh}$;

- Particulates: <0.025 g/kWh;

- HC: $<2 \mathrm{~g} / \mathrm{kWh}$ (compatible with a EUROV aftertreatment performances);

- CO: <5 g/kWh (compatible with a EURO V aftertreatment performances. No oil dilution (very important);

- Fuel consumption $<+4 \%$ (to be competitive with SCR approach);

- Compatible with standard air loop;

- Maximum peak pressure: 220 bar;

- Minimum compression ratio: 14:1 (starting condition).

\subsubsection{Injection Pressure}

Several tests have been performed with an early singleinjection approach from 600 bar to the maximum pressure allowed by the fuel injection system (1600 bar). The engine setting concerning the EGR rate and the equivalence ratio is always the same. In these conditions, the injection timing is adjusted to obtain the lower smoke emission. The best result in terms of smoke emission with fixed EGR rate and equivalence ratio is obtained with the maximum injection fuel pressure. As we can see on Figure 6, the smoke level decreases from 4.5 to 0.2 when the fuel pressure increases from 600 to 1600 bar.

As seen on Figure 7, higher injection pressure leads to an effective reduction of unburned hydrocarbons and carbon monoxide divided by 7 .

The smoke level curve also depends on the injection pressure but for early injection timing, no difference can be noticed. In general, at very early injection timings $\left(50^{\circ} \mathrm{CA}\right.$ before top dead center), low in-cylinder density and spray angle effects lead to fuel over penetration and probably impingement on cylinder liner surfaces which cause excessive smoke level (Fig. 8).

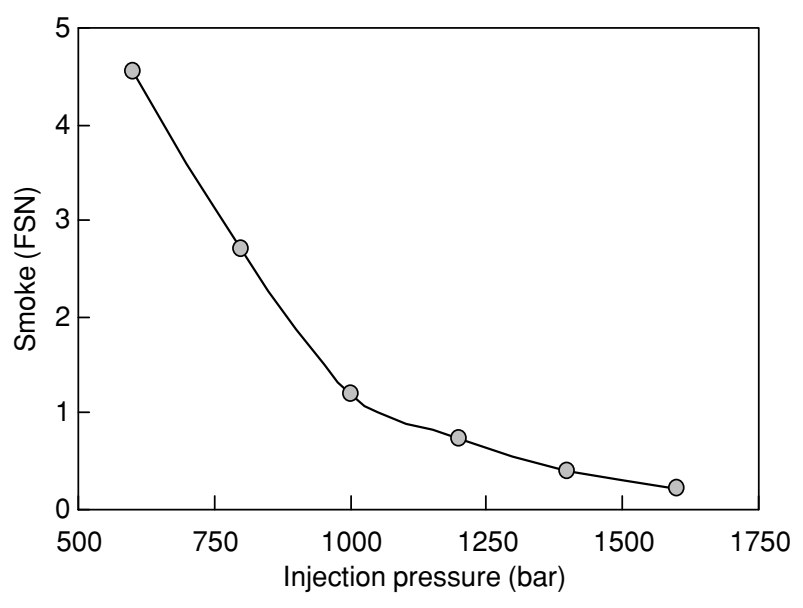

Figure 6

Effect of injection pressure on smoke level on B50.

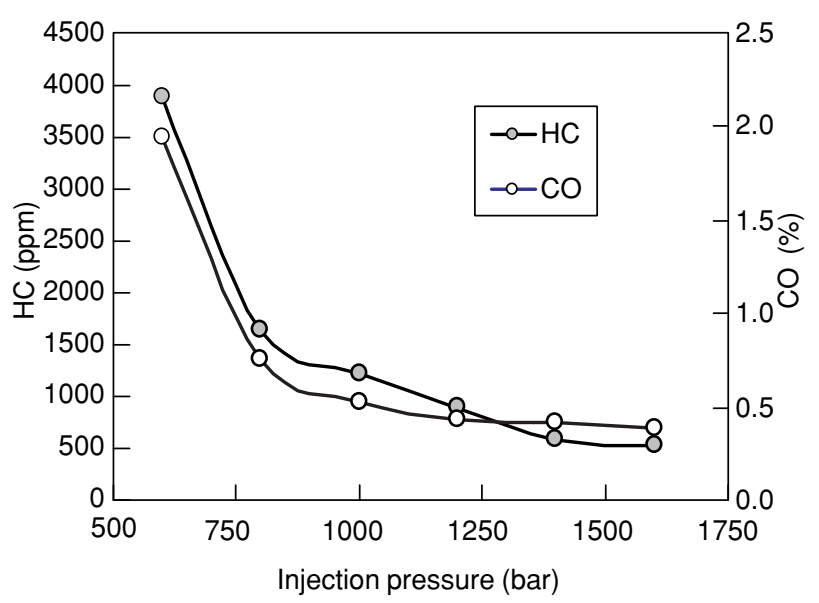

Figure 7

Effect of injection pressure on $\mathrm{HC}$ and $\mathrm{CO}$ emissions on B50.

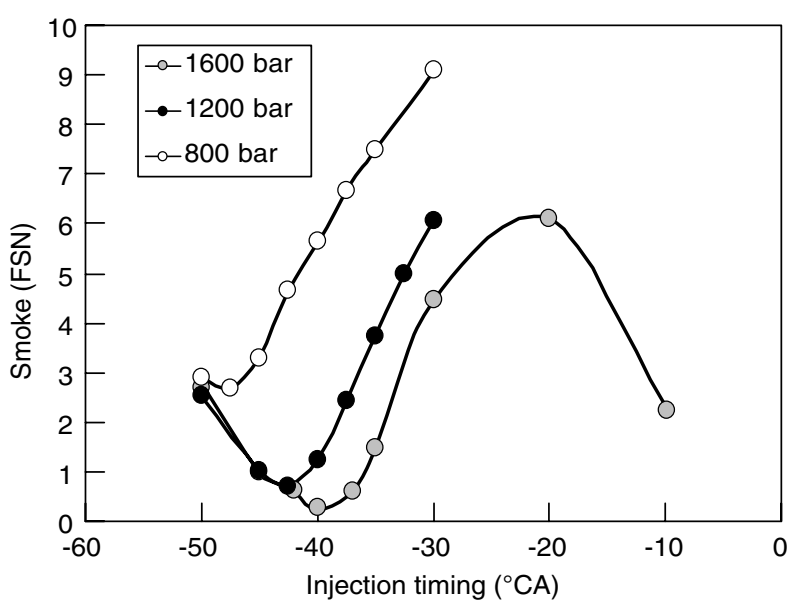

Figure 8

Effect of injection timing on smoke level at different injection pressure. 
In fact, for medium injection timing, the low smoke level is a result of the flow rate balancing the fuel introduced in combustion chamber during the auto-ignition delay, and the spray atomisation. For retarded injection timing, the smoke level decreases because of the increase of the auto-ignition delay. It is also possible to obtain a very low particulate emission level but with an important fuel penalty. In order to highlight the interest of the injection pressure, tests have been performed with two injectors with different fuel flow rates. Figure 9 presents the results obtained for optimised injection timing with lowest smoke level.

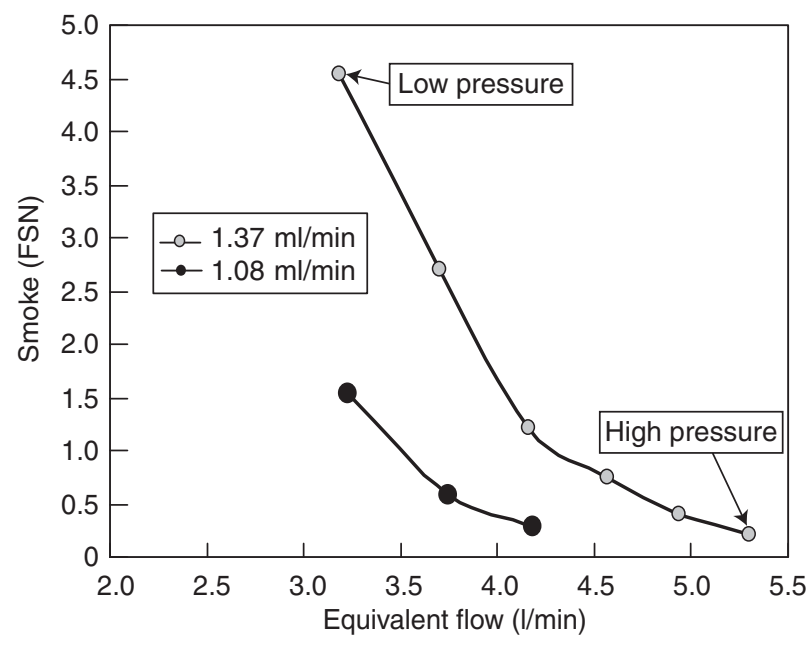

Figure 9

Effect of injection pressure on B50 for Z injection flows.

The $\mathrm{X}$-axis represents the equivalent flow in $1 / \mathrm{min}$ which is calculated as following:

$$
\text { Equivalent flow }(l / \mathrm{min})=\sqrt{(\operatorname{Inj} P-C y l P) / 100} \cdot \text { Injflow }
$$

- InjP: injection pressure (MPa);

- CylP: cylinder pressure at the beginning of injection (MPa);

- Inj flow: injector flow (1/min @ 10MPa).

With the same equivalent flow, the best results are obtained with the higher pressure.

\subsubsection{HPC Results with Single Injection}

The objective was to reach the highest load in accordance with the defined targets and with a maximum injection pressure of $160 \mathrm{MPa}$. The injection timing was adjusted to obtain the minimum smoke level with the best fuel consumption. The EGR temperature was close to $100^{\circ} \mathrm{C}$ compatible with a standard cooler efficiency. In these conditions the maximum load is 10 bar (50\% load) BMEP (Brake Mean Effective Pressure). The noise and the smoke level give the limit. The results obtained in term of emissions and noise for the B speed are plotted on Figure 10.

The HC level increase in comparison to the standard engine but is still compatible with a common after-treatment system. At low load, CO level is lower than the Cursor 8 engine. Nevertheless, equivalence ratio is increased close to the maximum HCCI load in order to keep the noise level below the objective. The consequence of this setting is an increase both in the carbon monoxide emission level at part load and in fuel consumption. As expected, the NOx level is below the target, more than 10 times lower than Cursor 8 engine. The particulate level is very low but slightly higher than the reference.

The fuel penalty for HCCI combustion in comparison to the results obtained with the standard engine is plotted on Figure 11. The results do not include turbocharger behavior: on single cylinder, exhaust back-pressure is higher than the intake pressure level to promote necessary condition for EGR. Taking into account these particular conditions, the HPC combustion has a positive impact at low load. Due to equivalent ratio setting and as a result of EGR rate and injection timing, the benefit is reduced so that fuel consumption is comparable up to $50 \%$ load (10 bar BMEP).

\subsubsection{HPC Results with Multiple Stage Injection}

One possibility offered by the NADI ${ }^{\mathrm{TM}}$ concept based on the narrow cone angle is to manage very early injections. This possibility have been tested under several conditions. If the interest is limited at low load (heat release controled with single injection), multiple injection opens new possibilities at part load and upper load. As shown on Figure12 for 50\% load on B speed condition, the multiple early injection allows for a better combustion control. The maximum heat release rate is $50 \%$ less and allows for a reduction of EGR and equivalence ratio setting without exeeding the maximum noise level allowed.

Thanks to the better homogeneous mixing due to the early injections, the $\mathrm{CO}$ emissions are divided by two. The better control of the combustion speed leads to a 4dB-noise reduction. Nevertheless, HC emissions are higher than with single injection and have to be treated to meet EURO V limitation. Notice that the intake pressure is lower (about 0.4 bar) and is more compatible with the turbocharger performances. The new settings allow for an extension of the HCCI range from 10 to 14 bar BMEP (50 to $70 \%$ load).

Multiple injection extends the HCCI Range without any penalty for fuel consumption (Fig. 13).

One of the severe constraints is the maximum in-cylinder pressure that limits the intake pressure improvement. Moreover, the EGR rate is at the minimum to reach the NOx objective. So, the way to increase the HPC range is the use of new injection strategies in odder to delay the combustion 

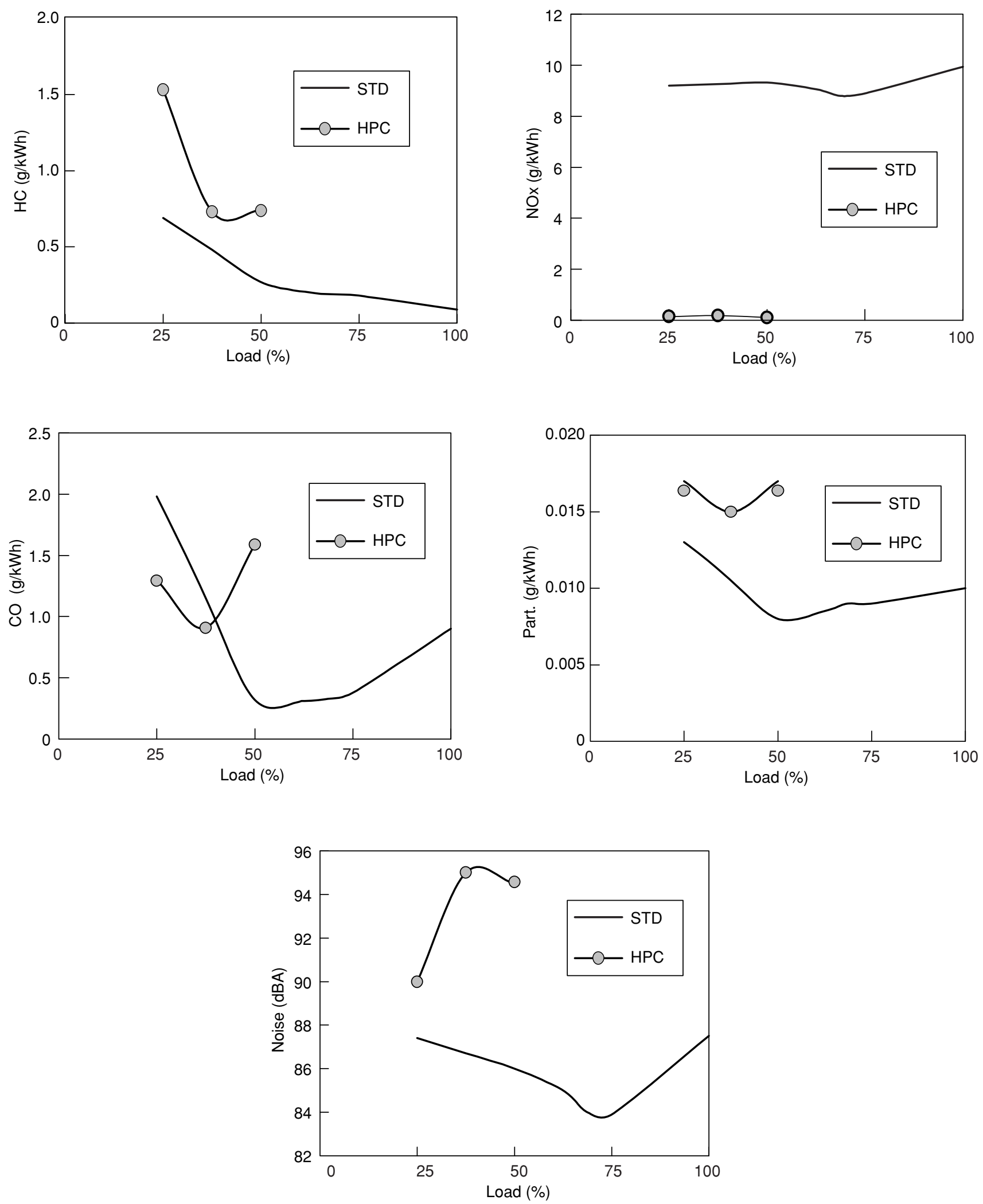

Figure 10

Results at B speed compared to the standard chamber. 


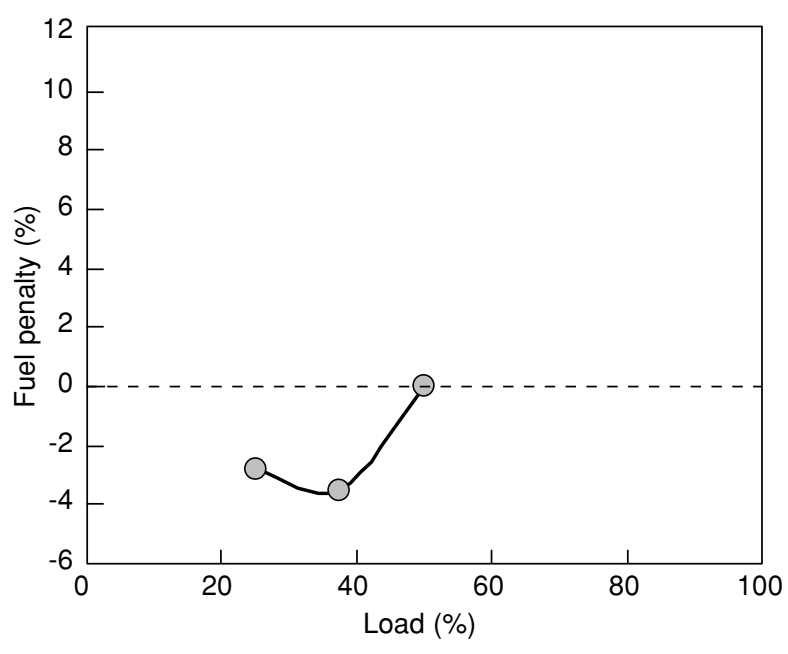

Figure 11

Fuel consumption with single injection compared with the standard chamber (without turbocharger effect).

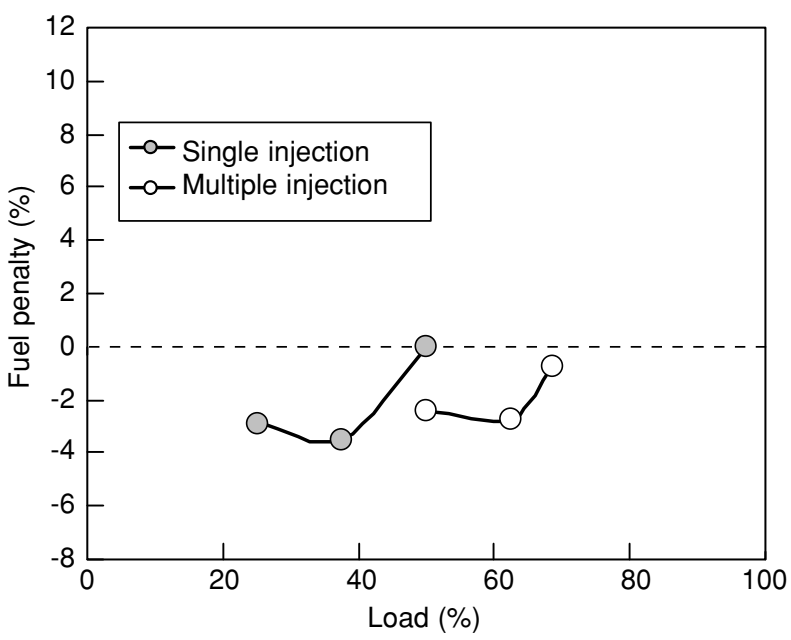

Figure 13

Fuel consumption with single and multiple injection compared with the standard chamber (without turbocharger effect).

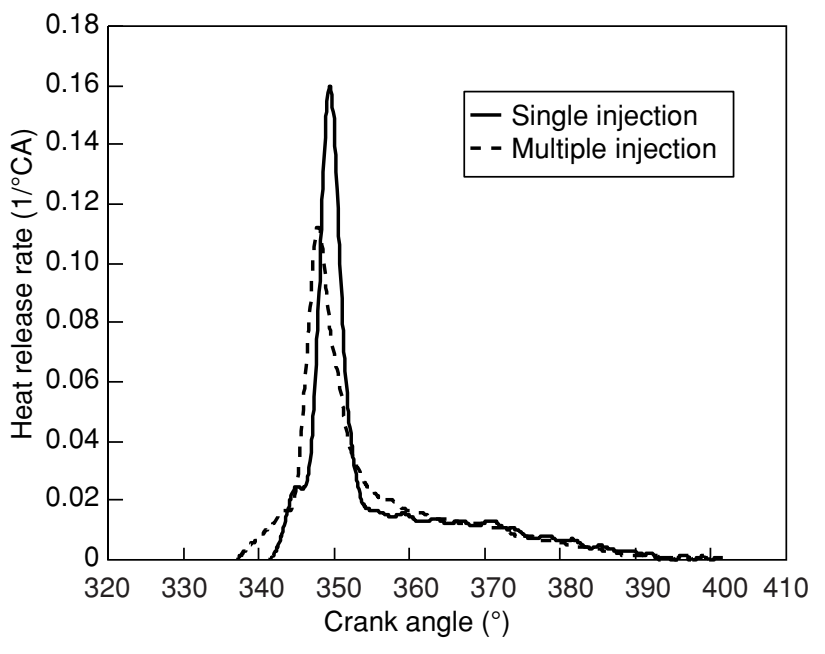

Figure 12

HRR with single and multiple injection .

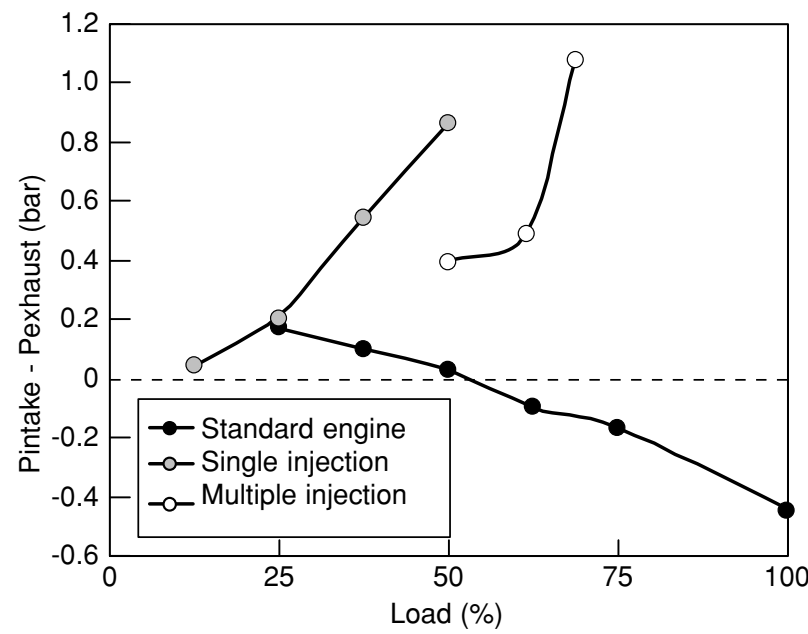

Figure 14

Turbocharger effect on low pressure loop efficiency. timing. The other way based on reducing the compression ratio will be discussed later.

\subsubsection{Air and EGR Loop Calculations}

OD calculations for a single stage turbocharger have been performed with IFP's in-house code. The results obtained quantify the impact of the air-loop on the feasibility of the HPC running conditions for a multicylinder engine.

Calculations have been performed with a variable geometry turbine. Its position is adjusted to obtain enough energy for the compressor driving. The results obtained in term of pressure difference between intake and exhaust is presented Figure 14.
At low load, the turbocharger effect is the same. When the BMEP increases, the power absorbed by the compressor to produce high-pressure charge is attainable with a closed turbine nozzle position. With a multiple injection approach, the limited EGR rate and the slight increase of exhaust temperature needed allow for more VNT opening and so limits the exhaust back pressure.

The corrected fuel consumption compared to the standard engine is presented on Figure 15.

The fuel penalty is limited up to a $40 \%$ load using single injection. For a higher load, the EGR needed to limit combustion noise is so great that the exhaust back pressure leads us to increase fuel penalty by more than $10 \%$. 


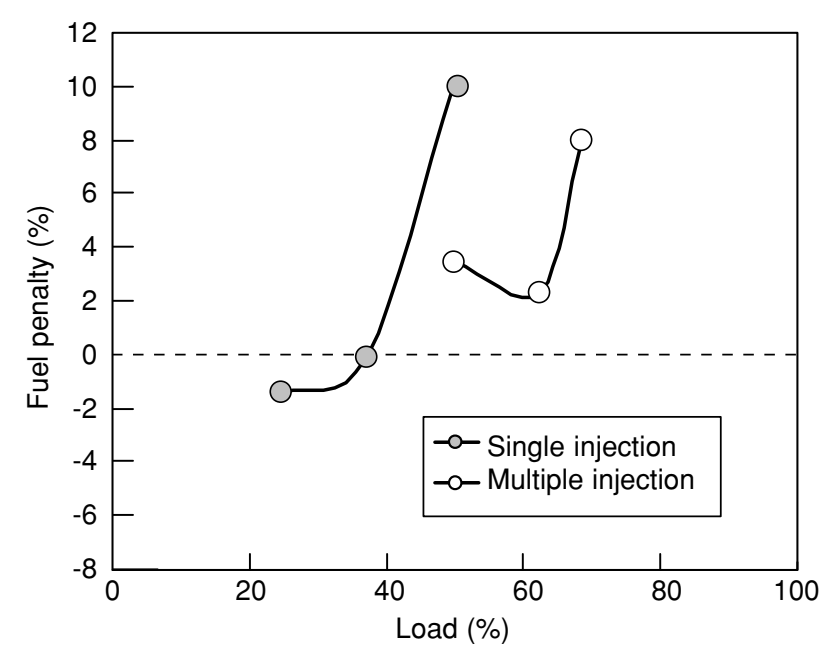

Figure 15

Fuel consumption with single and multiple injection compared with the standard chamber.

For the same load, the multiple injection allows us to limit fuel penalty by less than $4 \%$. With this setting and the single stage turbocharger, the maximum range for limited fuel penalty is about 13 bar (65\% load) of BMEP. For a higher load, the intake pressure needs to be reduced to limit the turbine power necessary, otherwise a double stage turbocharger adaptation is necessary.

One other aspect for HPC running condition is the power needed to cool the intake air and EGR mass flow. The calculations performed for a multicylinder engine in HCCI mode are compared to the standard engine on Figure 16.
The intake temperature increases from $40^{\circ} \mathrm{C}$ to $80^{\circ} \mathrm{C}$ when the load increases from 25 to $70 \%$. Those values have to be compared to the standard variation from $25^{\circ} \mathrm{C}$ to $50^{\circ} \mathrm{C}$ at full load conditions. In this case the cooling power is about 4 times higher than a common Diesel engine. This aspect should be taken into account for further application as a potential limitation to extend HCCI range.

The OD calculations also give also information on exhaust temperature downstream from the turbine as presented on the Figure 17.

If the HPC exhaust temperature is comparable to the serial engine up to $25 \%$ load, the difference between the two configurations reaches $100^{\circ} \mathrm{C}$ at $70 \%$ load. The maximum temperature for $\mathrm{HPC}$ combustion is about $250^{\circ} \mathrm{C}$. which assumes good oxidation catalyst efficiency to be able to treat the higher level of carbon monoxide and unburned hydrocarbons. The oxidation catalyst efficiency required to reach the EURO V target is about $70 \%$.

\subsubsection{Compression Ratio Effect}

As we can see above, one limitation of the HCCI range is the smoke level or the maximum in-cylinder pressure. The objective is also to introduce all the fuel during the auto ignition delay. So, one way for an HCCI range extension is to reduce the compression ratio. Two additional ratios have been tested, 12:1 and 10:1. A compression ratio of 10:1 was achieved with a new piston bowl chamber with the same dome angle and geometry as a compression ratio of 14:1. Because of the oil gallery proximity, it was not possible to attain the same bowl design with a compression ratio of 10:1. The combustion chamber volume was adjusted by increasing the squish volume.

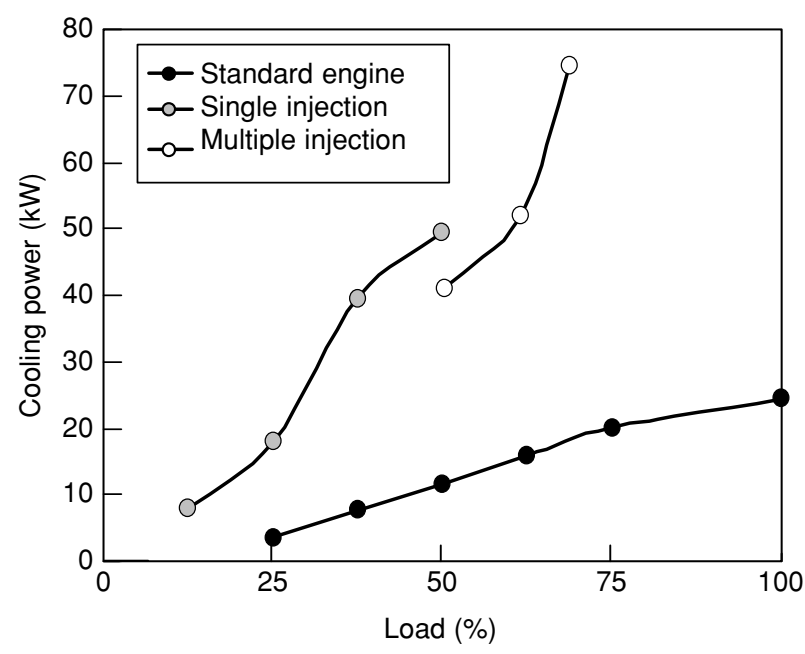

Figure 16

Air + EGR power for HCCI running conditions.

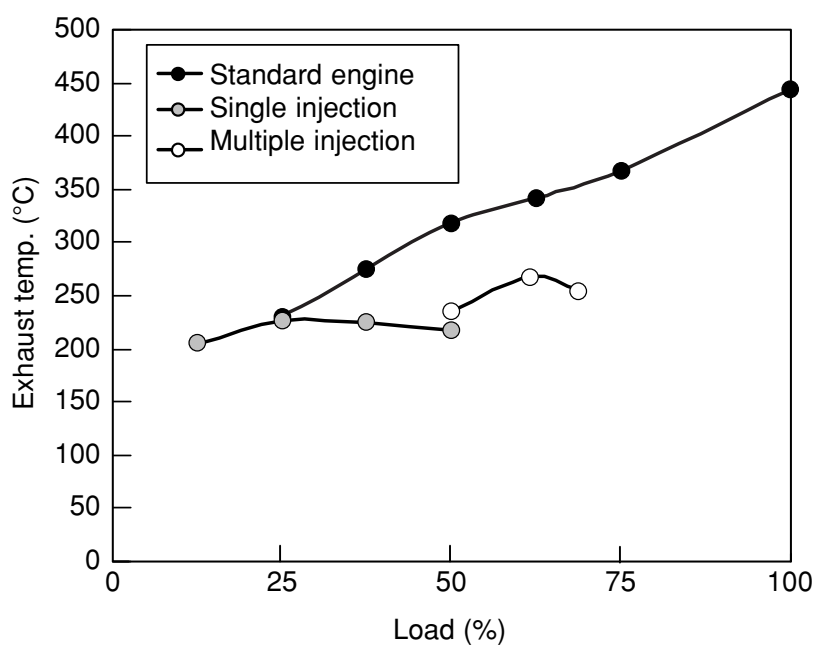

Figure 17

Exhaust temperature downstream from the turbine for different combustion modes. 
At a first time, tests were performed in 50\% load running conditions with the same EGR, equivalence ratio and injection setting. The heat release rate is presented on the Figure 18.

As we can see, the lower compression ratio allows for smooth combustion with better HRR phasing. With compression ratio reduction of 4 points, the noise level can be reduced by $8 \mathrm{dBA}$

The unburned hydrocarbons increase probably due to the lower in-cylinder density (wall impingement). These results are presented in Figure 19.

Figure 20 presents the smoke level versus injection timing. The smoke level is also significantly lower.

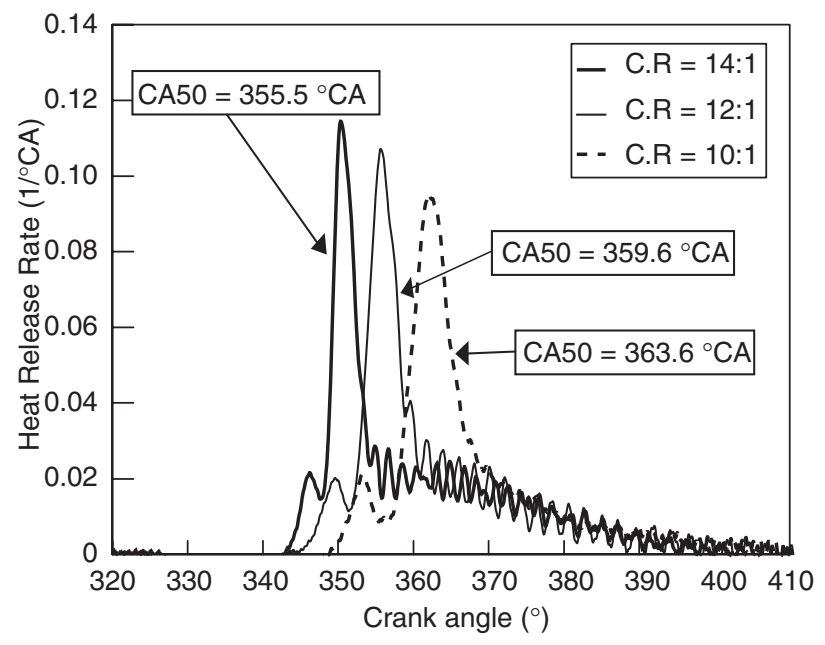

Figure 18

Heat release rate depending on compression ratio.

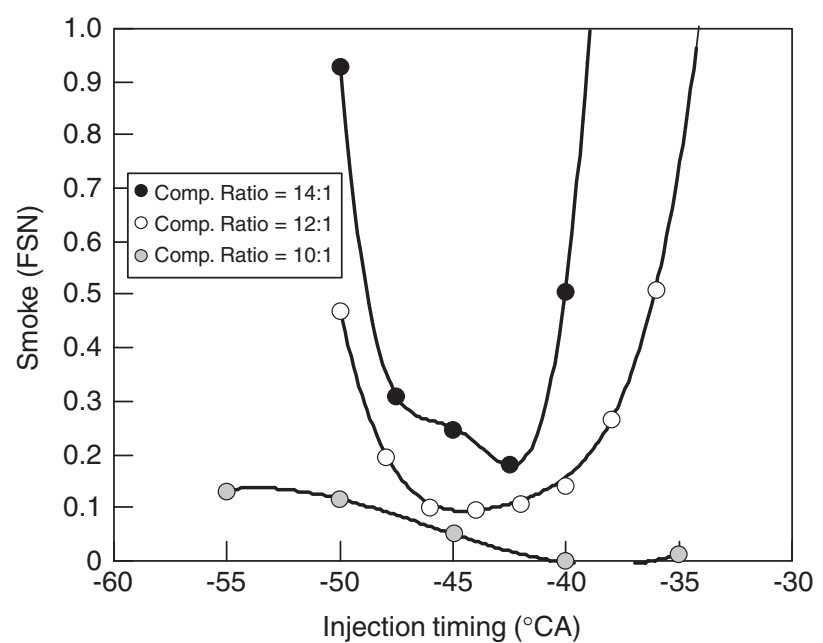

Figure 20

Smoke level depending on injection timing.
With the compression ratio of $14: 1$, the injection timing range in accordance with smoke level below the target is small: between $41 \mathrm{CA}$ and $47 \mathrm{CA}$. With a compression ratio of $10: 1$, the smoke target is attainable with an extended injection timing range. Of course the fuel penalty increases but can be limited to 5\%. Concerning the air loop, the reduced compression ratio allows to decrease the EGR rate without any combustion control difficulty. In these conditions, the intake pressure could be reduced and be more compatible with the turbocharger performances. Of course fuel consumption is higher (as discussed before) due to the reduced compression ratio but this drawback is minimised with the limited effect of the turbine on the exhaust back-pressure.

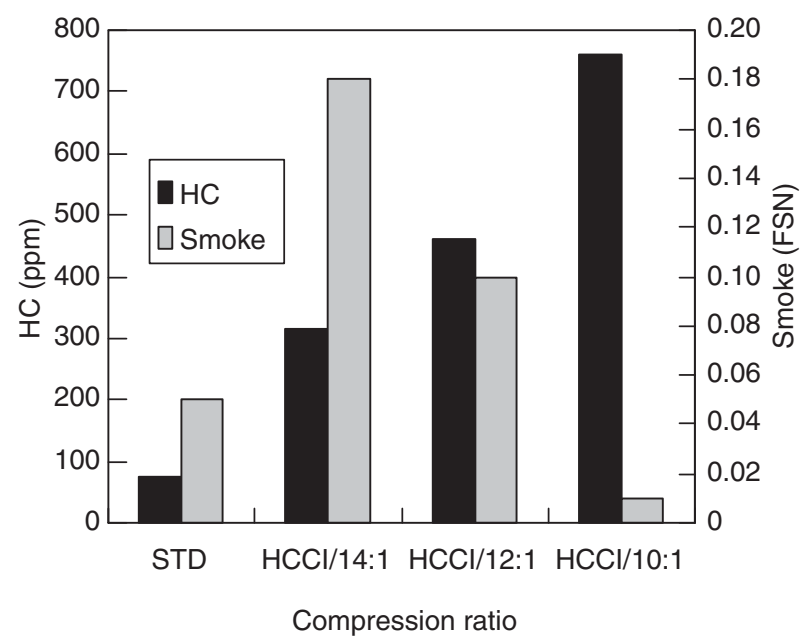

Figure 19

HC and smoke level compared to STD engine.

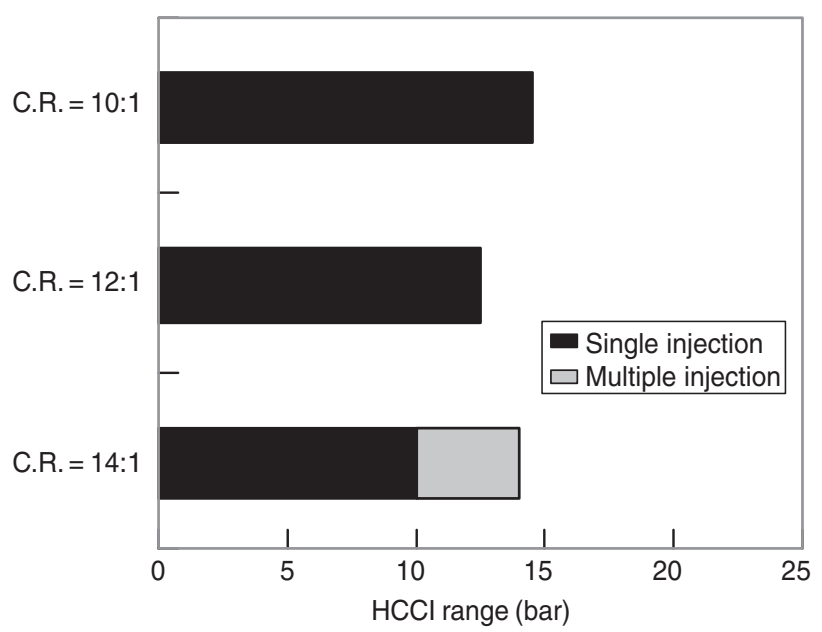

Figure 21

HCCI range with different compression ratio. 
The main advantage of reducing the compression ratio is the possible extension of the HCCI range. The limit for each value is presented on the Figure 21.

Multiple injection hasn't been tested with the lower compression ratio. It could be possible that the HCCI range should be extended by 3 or 4 bar more.

However, the cold starting difficulties and the lower efficiency should be major drawbacks for a reduction of compression ratio below 14:1.

\section{SUMMARY AND CONCLUSIONS}

The work carried out at IFP has allowed a first vision of the potential of adapting the NADI ${ }^{\mathrm{TM}}$ chamber to an heavy duty engine.

CFD calculations have allowed us to determine an adapted chamber which gives good results in conventional combustion. These NADI ${ }^{\mathrm{TM}}$ chamber performances compared to a standard engine with a higher compression ratio are not exactly similar but the difference is limited. For high BMEP ( $>50 \%$ load ) the fuel penalty is 1 or $2 \%$ higher with a slight increase in smoke level. The exhaust temperature is comparable to the serial engine. The carbon monoxide and unburned hydrocarbons emissions are slightly higher be still bellow EURO V target.

In HPC conditions, the maximum fuel injection system pressure is used to minimise the smoke level. The limitation was about 1600 bar and it seems that higher pressure should improve the results. High pressure is also beneficial for $\mathrm{HC}$ and $\mathrm{CO}$ emissions. It also make it possible to reduce smoke level by a increasing the fuel introduction speed and thus allowing for better combustion timing.

When the maximum range is reached with single injection, multiple injection opens new settings. It is possible to reduce noise and smoke emission with a fuel consumption reduction. It is also possible to reduce the EGR rate and increase equivalent ratio running conditions. These new settings create the possibility of extending the maximum HPC range up to a $70 \%$ load with the compression ratio of 14 .

No-dimensional calculations for a single stage turbocharger have been performed with IFP's in-house code. The results obtained showed that the high EGR rates needed to reach HCCI combustion have an important impact on the turbo-charger running conditions. The higher energy needed to drive the compressor goes to close the turbine. However, the consequence on exhaust back pressure is serious and has a negative effect on fuel consumption. Running with multiinjection settings, by the reduced EGR rate, allows a limitation of this drawback. The calculations show the high cooling (air + EGR) power needed to keep the intake temperature compatible with the HPC combustion. Therefore, the power and the exhaust back pressure limitations allow for an HCCI range up to 13 bar BMEP. The calculations also that the $\mathrm{HC}$ and $\mathrm{CO}$ emissions are compatible with exhaust temperatures and oxidation catalyst performances.

Reducing the compression ratio could be an alternative to extending the HCCI range up to a $75 \%$ load with single injection strategy (compared to 50\% with compression ratio of 14) but the cold starting difficulties and the limited efficiency could be serious drawbacks. A variable compression ratio engine is needed to consider using lower values than $14: 1$.

The major challenge is now to find new settings which should allow for an increase in HCCI range with reduction in EGR and intake mass flow. A two stage turbo-charger loop seems essential to limit the fuel penalty due to the exhaust back-pressure. New multi-injection settings and high injection pressure should be the solution to these problems.

\section{ACKNOWLEDGEMENT}

The authors would like to thank Wilfrid Robert who conducted the engine tests and Benjamin Reveille who performed the 3D calculations.

The authors are grateful to Delphi who prepared and delivered the fuel injection system and to Iveco who assist us for the engine.

Many thanks to European Commission for HySpace project funding.

\section{REFERENCES}

1 Walter, B., Monteiro, L., Miche, M. and Gatellier, B. (2004) Improvement of Exhaust and Noise Emissions of the NADI $^{\mathrm{TM}}$ Concept Using PreMixed Type Combustion with Multiple Stages Injection. SIA Paper.

2 Duffy, K., Fluga, E., Faulkner, S., Heaton, D., Schleyer, C. and Sobotowski, R. (2004) Latest Development in Heavy Duty Diesel HCCI. Which Fuels For Low $\mathrm{CO}_{2}$ Engine? Editions Technip.

3 Duffy, K., Fluga, E., Faulkner, S., Gutmann, P and Herzog, P.L. (2004) Passenger Vehicle Diesel Engines for the U.S. SAE paper 20004-01-1452.

4 Cowland, C., Gutmann, P. and Herzog, P.L. (2004) Passenger Vehicle Diesel Engines for the U.S. SAE paper 20004-011452.

5 Kahrstedt, J., Behnk, K., Sommer, A. and Wormbs, T. (2003) Combustion Processes to Meet Future Emission Standards. MTZ 10/2003.

6 Weissbäck, M., Csato, J., Glensvig, M., Sams, T. and Herzog, P. (2003) An Approach for Future HSDI Diesel Engines. MTZ 9/2003.

7 Umwelt Bundes Amt. (2003) Future Diesel - Exhaust Gas Legislation for Passenger Cars, Light-Duty Commercial Vehicles, and Heavy Duty Vehicles - Updating of Limit Values for Diesel Vehicles. www.umweltdaten.de/uba-infopresse/ hintergrund/FutureDiesel_e.pdf

8 Walter, B. and Gatellier, B. (2003) Near Zero NOx Emissions and High Fuel Efficiency Diesel Engine: the NADI ${ }^{\mathrm{TM}}$ Concept Using Dual Mode Diesel Combustion. Oil and Gas Science and Technology, 58, 1, pp. 101-114. 
9 Gatellier, B. and Walter, B (2002) Development of the High Power NADI ${ }^{\mathrm{TM}}$ Concept Using Dual Mode Diesel Combustion to Achieve Zero NOx and Particulate Emissions. Thiesel 2002 Conference on thermo- and fluid Dynamic Processes in Diesel Engines.

10 Walter, B. and Gatellier, B. (2002) Development of the High Power NADI ${ }^{\mathrm{TM}}$ Concept Using Dual Mode Diesel Combustion to Achieve Zero NOx and Particulate Emissions. SAE paper 2002-01-1744.

11 Gatellier, B., Walter, B. and Miche, M. (2001) New Diesel Combustion Process to Achieve near Zero NOx and Particulates Emissions. IFP International Congress - A new generation of engine combustion processes for the future?

12 Hultqvist, A., Engdar, U., Johansson, B. and Klingmann, J. (2001) Reacting Boundary Layers in a Homogeneous Charge Compression Ignition (HCCI) Engine. SAE Paper 2001-011032.

13 Kimura, S., Aoki, O., Kitahara, Y. and Aiyoshizawa, E. (2001) Ultra-Clean Combustion Technology Combining a Low - Temperature and Premixed Combustion Concept for Meeting Future Emission Standards. SAE Paper 2001-010200 .

14 Christensen, M. and Johansson, B. (2000) Supercharged Homogeneous Charge Compression Ignition (HCCI) with Exhaust Gas Recirculation and Pilot Fuel. SAE Paper 200001-1835.
15 Kimura, S., Aoki, O., Ogawa, H. and Muranaka, S. (1999) New Combustion Concept for Ultra-Clean and HighEfficiency Small DI Diesel Engines. SAE Paper 1999-013681.

16 Christensen, M., Hultqvist, A. and Johansson, B. (1999) Demonstrating the Multi Fuel Capability of a Homogeneous Charge Compression Ignition Engine with Variable Compression Ratio. SAE Paper 1999-01-3679.

17 Richter, M., Franke, A., Aldén, M., Hultqvist, A. and Johansson, B. (1999) Optical Diagnostics Applied to a Naturally Aspired Homogeneous Charge Compression Ignition Engine. SAE Paper 1999-01-3649.

18 Iwabuchi, Y., Kawai, K., Shoji, T. and Takeda, Y. (1999) Trial of New Concept Diesel Combustion System - Premixed Compression - Ignited Combustion. SAE Paper 1999-010185 .

19 Odaka, M., Suzuki, H., Koike, N. and Ishii, H. (1999) Search for Optimizing Method of Homogeneous Charge Diesel Combustion. SAE Paper 1999-01-0184.

20 Akagawa, H., Miyamoto, T., Harada, A., Sasaki, S., Shimazaki, N., Hashizume, T. and Tsujimura, K. (1999) Approaches to Solve Problems of the Premixed Lean Diesel Combustion. SAE Paper 1999-01-0183.

Final manuscript received in November 2005 